\title{
Synergistic Interactions Between Christia Vespertilionis Leaves Extract and Chemotherapy Drug Cyclophosphamide on WRL-68 Cell Line
}

\author{
Mutalib Nurliana Abd, Latip Normala Abd * \\ Atta-ur-Rahman Institute for Natural Products Discovery, University Teknologi MARA \\ Cawangan Selangor, 43200, Puncak Alam, Selangor, Malaysia
}

\begin{abstract}
A B S T R A C T
Christia vespertilionis locally known as 'rerama' has gained much attention as herbal preparation to treat various ailments and diseases although there is no conclusive evidence of its therapeutic values. Self-medication is commonly practiced by patients, underpinned by health believes that affect their adherence to medication regimens, and impacting on treatment outcomes. Therefore, in this study the phytochemical profile and potential interaction of this plant extracts with conventional chemotherapy drug cyclophosphamide were investigated. Water decoction and maceration method with $70 \%$ ethanol were used to extract the plant leaves. Phytochemical profiling of the extracts and compound identification was done using HPLC. Isoorientin was identified as the major phytochemical component of the extracts.MTT assay was used to screen cytotoxicity of the extract towards CRL2522, HaCaT, HepG2, MCF-7 and WRL68 cell lines. Combination index (CI) and isobologram were derived from combination treatment of extract and cyclophosphamide. Ethanolic extract has low cytotoxicity against all cell lines (IC50>1 mg/mL). However, combination treatment of ethanolic extract and cyclophosphamide at IC15 and IC25 concentration resulted in synergism $(\mathrm{CI}<1)$. There is potential synergism arise with combination treatment of this plant with cyclophosphamide, which enhances cytotoxicity and the mechanism of synergism worth to be further investigated.
\end{abstract}

Key words: Christia vespertilionis, rerama, cyclophosphamide, drug-herb interaction

A R T I C L E I N F 0: Received 01 March 2019; $\quad$ Review Completed 16 M ay 2019; Accepted 16 June 2019; Available online 20 June 2019

Cite this article as:

Mutalib NA, Latip N A*, Synergistic Interactions Between Christia Vespertilionis Leaves Extract and Chemotherapy Drug Cyclophosphamide on WRL-68 Cell Line,, Asian Journal of Pharmaceutical Research and Development. 2019; 7(3):109-113 DOI: http://dx.doi.org/10.22270/ajprd.v7i3.488

*Address for Correspondence:

Normala Abd Latip, Atta-ur-Rahman Institute for Natural Products Discovery, University Teknologi MARA Cawangan Selangor, 43200, Puncak Alam, Selangor, Malaysia

\section{INTRODUCTION}

$\mathrm{T}$ hroughout history, herbal medicines are utilized by many cultures and known as the oldest form of healthcare. Since the early time, the diverse plant resources have been a major contributor towards human'sshelter, food, clothing, and medicines as cure for countless illness ${ }^{1}$.For the past 20 years, the use of herbal as complementary alternative medicines has dramatically increased $^{2}$.

It is difficult to estimate accurately the prevalence of the usage and co administration of herbal products with conventional medicine because health care providers are rarely informed by patients who self-medicate with herbal remedies ${ }^{3}$. Complementary medicines including herbal products are often consumed in the context of polypharmacy. It was found in a study that $32.5 \%$ of 3070 elderly people consume three or more prescription medicines with three or more complementary medicines and $74.2 \%$ of them took at least one prescription drug and one complementary medicine which highly pose risk of drug interactions 4 .

In 2004, the term "herb-drug interactions" was introduced as a Medical Subject Headings (MeSH) term and defined as "the effect of herbs, other plants, or plant extracts on the activity, metabolism, or toxicity of drugs." . Medicinal plants and the phytochemicals derived from them are increasingly known and used as complementary treatments for cancer for instance paclitaxel, docetaxel, curcumin etc. Chemotherapy functions to kill or suppress tumour cells while preserving the normal cells in the body and it represents one of the major means for cancer treatment, which usually used in combination that given at a maximum tolerated dose to achieve maximum efficacy ${ }^{6}$. Cyclophosphamide is a chemotherapy drug classified as alkylating agent that interferes with DNA replication and 
is toxic torapidly dividing cells which is used to treat malignancy, severe systemic lupus erythematosus (SLE), and vasculitis?

An ornamental plant, Christia vespertilionis (L.) Bakh. f. (syn. Laurea vespertilionis, Hedysarum vespertilionis; Family-Fabaceae) is commonly known as 'Mariposa' or 'Red butterfly wing' due to the similarity of its leaves to a butterfly shape, is used to treat tuberculosis, bronchitis, inflamed tonsils, fever, muscle weakness, poor blood circulation and also topically used as a cure for scabies ${ }^{8}$. The usage of $C$. vespertilionis decoction as an alternative medicine to the modern treatment in battling cancer has been popular in Malaysia recently thus this plant is distributed and formulated as tea throughout Malaysia by traditional practitioners ${ }^{9}$. It has gained a huge popularity among Malaysians thus is it crucial to study potential interaction that this plant might pose with drug treatment.

\section{METHODS}

\section{Extraction of $C$. vespertilionis}

Dried $C$. vespertilionis leaves powder was extracted according to method described previously ${ }^{10}$ with slight modifications. For ethanolic extract, $50 \mathrm{~g}$ of powder sample in $500 \mathrm{~mL}$ of $70 \%$ ethanol was sonicated for 30 minutes before solvent removal at $40{ }^{\circ} \mathrm{C}$ using rotary evaporator. For aqueous extraction, slightly modified method described before was used ${ }^{11} .100 \mathrm{~g}$ of powdered sample was boiled in $200 \mathrm{~mL}$ of water for 60 minutes and was vacuum filtered after cooling at room temperature. The supernatant of aqueous extract/and residue of ethanolic extract after solvent removal were freezed at $-80{ }^{\circ} \mathrm{C}$ and lyophilized using freeze dryer on the next day ${ }^{12}$. The extraction yield of each extract was calculated using equation (1)

Percentage extraction yield $=$ (mass of extract $/$ mass of sample) $\times 100$

\section{Total Phenolic Content}

The total phenolic content of the extracts was quantified using Folin-Ciocalteu reagent method ${ }^{13}$. Extracts were dissolved in water $(1 \mathrm{mg} / \mathrm{mL})$. $1 \mathrm{~mL}$ of Folin-Ciocalteu reagent and $0.8 \mathrm{~mL}$ of $7.5 \%(\mathrm{w} / \mathrm{v})$ sodium bicarbonate $\left(\mathrm{Na}_{2} \mathrm{CO}_{3}\right)$ were added to $0.2 \mathrm{~mL}$ of extract. The mixture was incubated for 1 hour at room temperature and the absorbance at $760 \mathrm{~nm}$ was measured using spectrophotometer. Six point calibration curve was plotted with 6 concentrations of gallic acid $(0.02$ to $0.30 \mathrm{mg} / \mathrm{mL})$.

\section{Total Flavonoid Content}

Procedure described previously was used with slight modification $^{14}$. $500 \mu \mathrm{L}$ of extract stock $(1 \mathrm{mg} / \mathrm{mL}$ in methanol), $1.5 \mathrm{ml}$ methanol, $100 \mu \mathrm{L} 1 \%$ aluminium chloride, $100 \mu \mathrm{L} 1 \mathrm{M}$ potassium acetate solution and $2.8 \mathrm{ml}$ distilled water were added in well. After 30 minutes incubation at room temperature, absorbance was measured at $415 \mathrm{~nm}$. Calibration curve of quercetin at 20, 40, 60, 80 and $100 \mu \mathrm{g} / \mathrm{mL}$ was plotted.

\section{UHPLC ANALYSIS}

$1 \mathrm{mg} / \mathrm{mL}$ extract was prepared in $80 \%$ methanol and filtered. All standards are prepared at $100 \mathrm{ppm}$ in $100 \%$ methanol. HPLC conditions described in a previous study used with modifications ${ }^{15}$. Extracts were analysed using
Dionex Ultimate 3000 UHPLC systems equipped with Diode Array Detector (Thermo Fisher Scientific Inc., MA, USA). Separations were performed on a reverse-phase Luna C18 (150×4.6 mm i.d., $5 \mu \mathrm{m}$ particle size) analytical column (Phenomenex, Torrance, CA, USA). Separation operated at column oven temperature of $28^{\circ} \mathrm{C}$ at a flow rate of $0.6 \mathrm{~mL} / \mathrm{min}$. The mobile phases " $\mathrm{A}$ " and " $\mathrm{B}$ " consist of a mixture of water and acetonitrile respectively. A $10 \mu \mathrm{L}$ injection volume was injected and elution gradient for the separation as follows: initial $17 \% \mathrm{~B}, 0-12$ min, $17-25 \% \mathrm{~B}$; $12-14 \mathrm{~min}, 25 \% \mathrm{~B}$; $14-15 \mathrm{~min}, 25-17 \% \mathrm{~B}$; $15-17 \mathrm{~min}, 17 \%$ B. Detection was carried out at wavelength of $360 \mathrm{~nm}$.

\section{MTT ASSAY}

MTT assay was conducted following the method described previously with modifications ${ }^{16}$. Seeding of $5 \times 10^{3}$ cells per well was done followed by incubation for 24 hours. $90 \%$ confluence cell culture in 96 well plate was treated with $100 \mathrm{ul}$ of extracts at different concentration $(0-5 \mathrm{mg} / \mathrm{ml})$ and positive control (cisplatin at $0.25 \mathrm{mM})$. After 24 hours incubation, $20 \mu \mathrm{L}$ MTT solution $(5 \mathrm{mg} / \mathrm{mL}$ in PBS) was added into each well and incubated for 4 hours. DMSO was added $50 \mu \mathrm{L}$ per well and absorbance value was measured at $570 \mathrm{~nm}^{17}$. This assay was repeated with cyclophosphamide treatment at different concentrations $(0-50 \mathrm{mM})$. The assay was also repeated with combination of extract and cyclophosphamide on WRL68 at different ratio. $\mathrm{IC}_{50}$ and Combination Index (CI) values were calculated and isobolograms were constructed. Equation 2 shows the formula to calculate CI values:

$\mathrm{CI}=\left(\mathrm{IC} 50_{\text {extract }}\right.$ combination $/ \mathrm{IC} 50_{\text {extract }}$ single $)+\left(\mathrm{IC} 50_{\text {drug }}\right.$ combination / IC50 drug single) (2)

\section{RESULTS AND DISCUSSION}

The extraction yield is strongly influenced by the solvent, due to the different polarity and different compounds extracted $^{18}$. Apart from solvent, extraction technique and temperature have effect on extraction yield as well. Table 1 summarized the extraction conditions and extraction yield of ethanolic and aqueous extracts of $C$. vespertilionis.

The extraction yield of ethanolic extract is lower than that of aqueous extract. However, it is crucial to point out that high extraction yield may not be translated to a higher phytochemical content such as phenolic compounds including flavonoids. Therefore, TPC and TFC of the extracts were evaluated and results demonstrated in Figure 1. Both TPC and TPF of C. vespertilionis ethanolic (A) extract are higher compared to aqueous (B) extract. 95\% ethanol was used in extraction of extract $\mathrm{A}$ as solvent plays an important role in extraction of phenolic compounds. A study was done on olive leaves revealed that $100 \%$ ethanol was not an efficient solvent for phenolic compounds extraction ${ }^{19}$. However, addition of water to ethanol changes the solvent physical properties thus modified the solubility and enhances the diffusion of phenolic compounds through plant tissues ${ }^{20}$. A previous study suggested that water was not an efficient extractant in extraction of phenolic compounds ${ }^{21}$.

In this study water extraction was done at $100^{\circ} \mathrm{C}$ to mimic traditional preparation of the plant. Although increase in temperature does decrease viscosity and increase the 
diffusion rate during extraction, high temperature also causes degradation of phenolic compounds ${ }^{22}$. In addition, flavonoids are also heat-sensitive and high extraction temperature lead to compound degradation ${ }^{23}$. HPLC profiling of both extracts as well as compound identification were conducted and chromatograms are shown in Figure 2.

The comparison of phytochemical profiles of both extracts further confirms significant amount of phytochemicals were lost during extraction process of aqueous extract. This supports that higher yield of extraction does not necessarily reflect in higher phytochemical content such as phenolic compounds because the higher extraction yield of aqueous extract may due to abundant carbohydrates that is undetectable by UV-VIS spectra. In a previous study by, two flavonoid glycosides were identified in $C$. vespertilionis extract which arequercetin$3-O-$ glucoside and catechin-3-O- $\beta$-D-glucopyranoside ${ }^{8}$. In this study, another two known flavonoid glycosides, schaftoside and isoorientin were identified in both extracts and the latter is the major phytochemical component of both extracts. Extract with highest TPC and TFC, ethanolic extract (A) was screened for cytotoxicity on a panel of cell lines which are fibroblast (CRL2522), keratinocyte (HaCaT), liver carcinoma (HepG2), breast cancer (MCF-7) and normal liver (WRL68). The IC50 values of extract $\mathrm{A}$ against each cell line are $1.509 \pm$ $0.072,1.221 \pm 0.016,1.630 \pm 0.027,1.744 \pm 0.034$ and $1.934 \pm 0.022$ respectively as shown in Figure 3. Overall, ethanolic extract (A) showed low cytotoxicity against all cell line as the IC50 values exceed $1 \mathrm{mg} / \mathrm{mL}$. According to National Cancer Institute (NCI), the established criteria of cytotoxicity for the crude extract is an IC50 of $20 \mu \mathrm{g} / \mathrm{mL}$ and below in the preliminary assay ${ }^{24}$.
WRL68 normal liver cell line was used to proceed with combination treatment of $C$. vespertilionis ethanolic extract and cyclophosphamide. This is because cyclophosphamide is extensively metabolized in the liver by cytochrome P450 enzymes via activation process 4 hydroxylation producing active metabolite, 4hydroxycyclophosphamide that penetrates the cell membrane which then decomposes to phosphoramide mustard that alkylates $\mathrm{DNA}^{25}$. The combination index derived from the combination treatment tabulated in Table 2

Combination treatment of $C$. vespertilionis ethanolic extract and cyclophosphamide at concentration of IC10 resulted in antagonism as the CI value is more than 1 (1.359). However, combination treatment at IC15 and IC25 showed synergism with CI value of 0.674 and 0.466 respectively. Figure 3 demonstrates isobologram that further explains the CI values. IC10 plot falls above the line of additivity which indicates antagonism. Both IC15 and IC25 plots are below the line of additivity which indicates synergistic effect from the combination treatment. Isoorientin is the major phytochemical component identified in ethanolic extract A. Previous study revealed that isoorientin induces HepG2 apoptosis by stimulating ROS formation which causes uncontrollable physiological response that eventually lead to cellular damage ${ }^{26}$. In addition, isoorientin was also reported to have impact on colorectal cancer cells proliferation via cell cycle pathways and alteration ofapoptosis gene expression ${ }^{27}$. These evidences demonstrated that isoorientin mechanism of actions affecting cell proliferation could contribute to the synergism resulted from combination treatment of ethanolic extract (A) with cyclophosphamide. However, more studies are needed to further elucidate and confirm its synergistic mechanism of actions.

Table 1: Yield of extraction of $C$. vespertilionis aqueous and ethanolic extracts.

\begin{tabular}{|l|l|l|}
\hline Extract code & Extraction condition & Yield of extraction \% \\
\hline A & $70 \%$ ethanol, sonication, 30 minutes & 6.40 \\
\hline B & Water, decoction $100^{\circ} \mathrm{C}, 60$ minutes & 7.67 \\
\hline
\end{tabular}

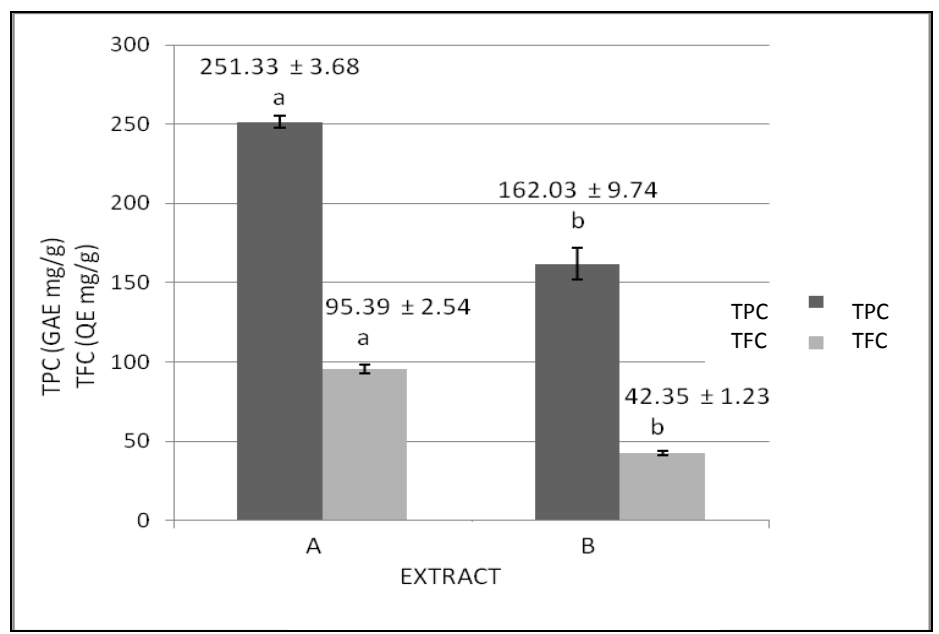

Figure 1: Total phenolic content and total flavonoid content of ethanolic (A) and aqueous (B) extracts of C. vespertilionis. Bars with different letters denoted that the mean values were significantly different between extracts ( $t$-test, $\mathrm{p}<0.05)$ 


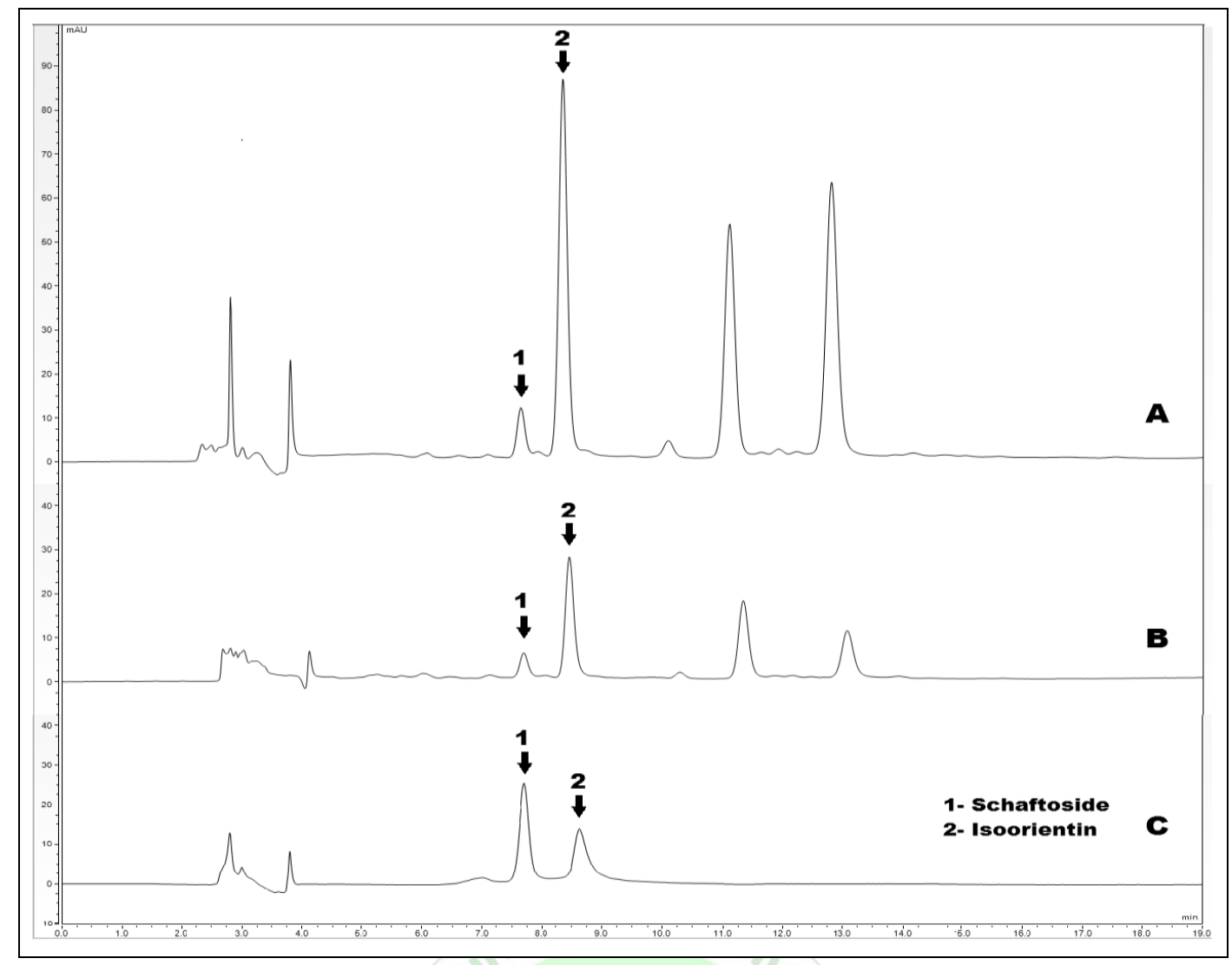

Figure 2: HPLC Chromatograms of A: Ethanolic extract profile, B: Aqueous extract profile and C: Flavonoid standards (schaftoside and isoorientin)

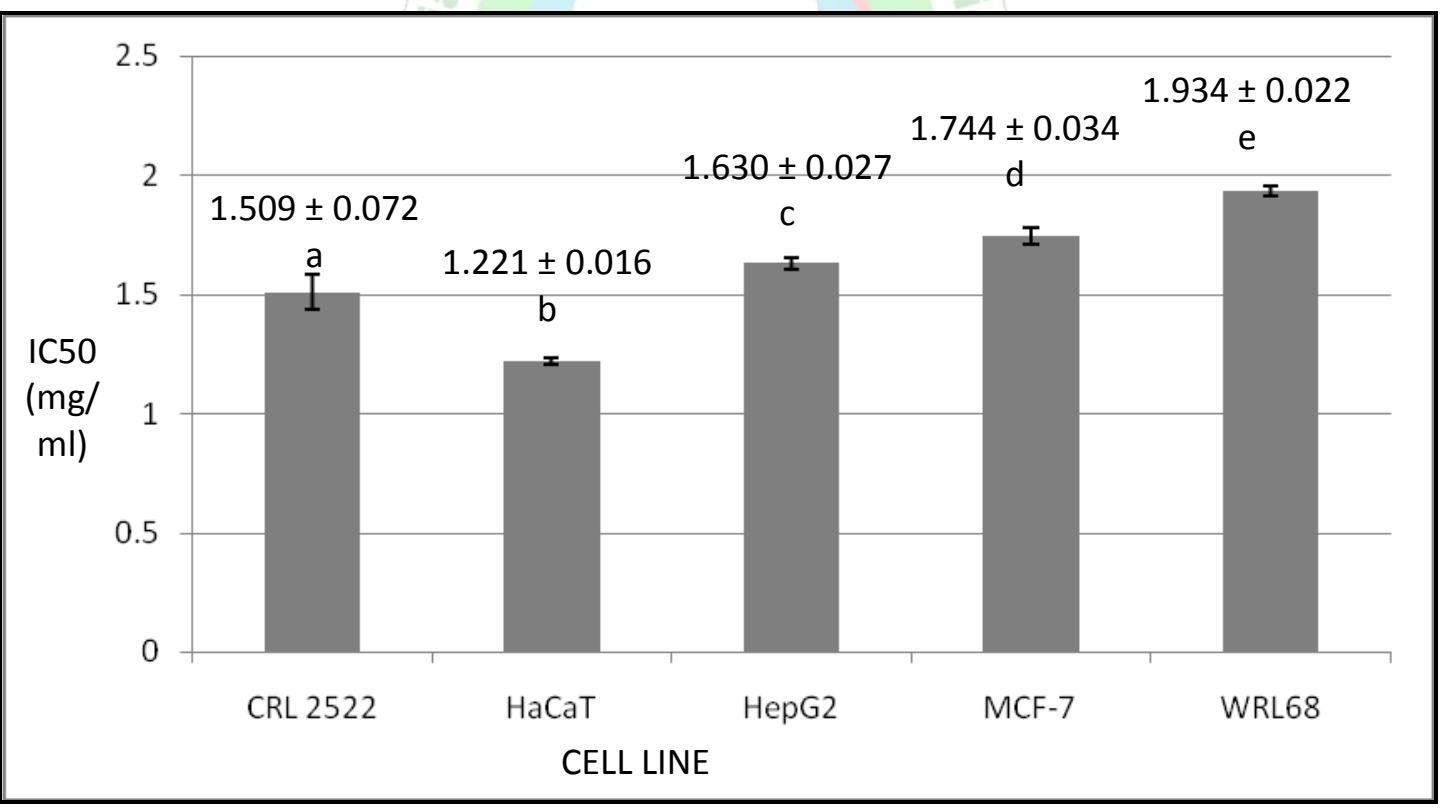

Figure 3: IC50 value (Mean \pm SEM) of C. vespertilionis ethanolic extract against CRL 2522 (fibroblast), HaCaT (keratinocyte), HepG2 (liver carcinoma), MCF-7 (breast cancer) and WRL68 (normal liver) cell lines. Bars with different letters denoted that the IC50 values were significantly different between cell lines (one-way ANOVA, followed by post-hoc Tukey's test, $\mathrm{p}<0.05$ )

Table 2: Combination Index

\begin{tabular}{|l|l|l|l|l|}
\hline Combination Treatment & FIC CX & FIC CV & Combination Index (CI) & Description \\
\hline CX + CV IC10 & 0.775 & 0.584 & 1.359 & Antagonism \\
\hline CX + CV IC15 & 0.172 & 0.502 & 0.674 & Synergism \\
\hline CX + CV IC25 & 0.106 & 0.360 & 0.466 & Synergism \\
\hline
\end{tabular}




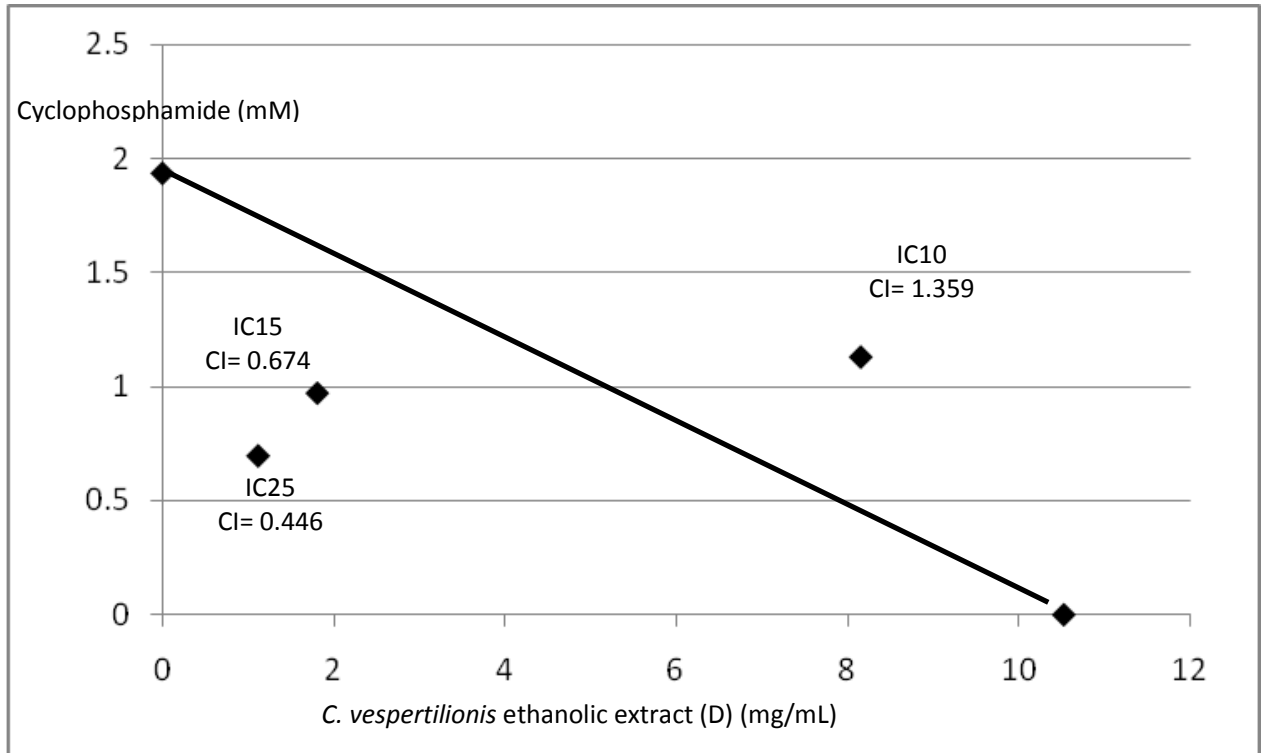

Figure 3: Isobologram of combination treatment of C. vespertilionis ethanolic extract (D) and cyclophosphamide against normal hepatocyte cell line WRL68).

\section{CONCLUSION}

Combination treatment of ethanolic extract (A) at higher concentration with cyclophosphamide resulted in synergism and worth to be further investigated on the mechanism of actions.

\section{REFERENCES}

1. Kunle FO, Egharevba OH, Ahmadu, \& Ochogo P. Standardization of herbal medicines - A review. International Journal of Biodiversity and Conservation, 2012; 4(3):101-112.

2. Ghagane SC, Puranik SI, Kumbar VM, Nerli RB, Jalalpure SS, Hiremath M, \& Aladakatti R. In vitro antioxidant and anticancer activity of Leea indica leaf extracts on human prostate cancer cell lines. Integrative Medicine Research, 2017; 6(1):79-87.

3. Brantley SJ, Argikar AA, Lin YS, Nagar S, \& Paine M F. Herb-drug interactions: challenges and opportunities for improved predictions. DruG Metabolism and Disposition, 2013; 42(3):301-317.

4. Moses GM \& Mcguire TM. Drug interactions with complementary medicines. Australian Prescriber, 2010; 33(6):177-180.

5. Yeung $\mathrm{S} \&$ Gubili J. Herb-drug interactions in cancer care. Oncology, 2018; 32(10):516-20.

6. Zhou S. Toxicology, safety and herb-drug interactions in cancer therapy. Supportive Cancer Care with Chinese Medicine, 2009; 293340

7. Deakin CT, Campanilho-Marques R, Simou S, Moraitis E, Wedderburn LR, Pullenayegum E, \& Pilkington CA. Efficacy and safety of cyclophosphamide treatment in severe juvenile dermatomyositis shown by marginal structural modeling. Arthritis \& Rheumatology, 2018; 70(5):785-793

8. Upadhyay H C, Sisodiab BS, Cheemab HS, Agrawalb J, Palb A, Darokarb MP \& Srivastavaa SK. Novel antiplasmodial agents from christia vespertilionis. Natural Product Communications, 2013; 8:1

9. Bunawan H, Bunawan SN. \& Syarul B. The red butterfly wing (Christia vespertilionis): a promising cancer cure in malaysia. International Journal of Pharmacy and Pharmaceutical Sciences, 2015; 7(8)

10. Quah, SY, Chin JH, Akowuah GA, Khalivulla SI, Yeong SW\& Sabu MC. Cytotoxicity and cytochrome P450 inhibitory activities of Clinacanthus nutans. Drug Metabolism and Personalized Therapy, 2017; 32(1).

\section{ACKNOWLEDGEMENT}

The authors acknowledge the funder of this research, RMC UiTM under MITRA grant (600-IRMI/MYRA 5/3/MITRA (004/2017)-2).

\section{Disclosure statement}

No potential conflict of interest was reported by the authors.

11. Al-Manhel AJ, \& Niamah AK. Effect of aqueous and alcoholic plant extracts on inhibition of some types of microbes and causing spoilage of food. Journal of Nutrition \& Food Sciences, 2015; S5.

12. Bohlooli S, Jafari N, \& Jahed S. Cytotoxic Effect of freeze-dried extract of Ecballium elaterium fruit on gastric adenocarcinoma (AGS) and esophageal squamous cell carcinoma (KYSE30) cell lines. Journal of Gastrointestinal Cancer, 2012; 43(4):579-583.

13. Aziz A \& Jack R. Total phenolic content and antioxidant activity in Nypa fruticans extracts. Journal of Sustainability Science and Management, 2015; 10(1):87-91.

14. Kalita Pallab \& Barman TK \& Pal Tapas \& Kalita, Ramen. Estimation of total flavonoids content (TFC) and antioxidant activities of methanolic whole plant extract of Biophytum sensitivum Linn. Journal of Drug Delivery and Therapeutics. 2013; 3

15. Chelyn JL, Omar MH, Yousof SAM, Ranggasamy R, Wasiman M I, and Ismail Z. Analysis of flavone C-glycosides in the leaves of Clinacanthus nutans (Burm. f.) Lindau by HPTLC and HPLCUV/DAD. Sci. World J, 2014; 2014: 1-6.

16. Norfazlina MN, Farida Zuraina MY, Rajab NF, Mohd Nazip S, Rumiza AR, Sakdarat S, Shuyprom A, Pientong C, Ekalaksananan, T, \& Thongchai S. Bioactive constituents from the leaves of Clinacanthus nutans Lindau. Bioorganic \& Medicinal Chemistry, 2009; 17(5):1857-1860.

17. Patel J, Amrutiya J, Bhatt P, Javia A, Jain M, Misra A. Targeted delivery of monoclonal antibody conjugated docetaxel loaded PLGA nanoparticles into EGFR overexpressed lung tumour cells. Journal of Microencapsulation. 2018; 35(2):204-17.

18. Bilek SE. The effects of time, temperature, solvent: Solid ratio and solvent composition on extraction of total phenolic compound from dried olive (Olea europaea L.) leaves. GIDA, 2010; 35: 411-416.

19. Altıok E, Bayçın D, Bayraktar O, \& Ülkü S. Isolation of polyphenols from the extracts of olive leaves (Olea europaea L.) by adsorption on silk fibroin. Separation and Purification Technology, 2008; 62(2):342-348 
20. Cacace J E, \& Mazza G. Optimization of extraction of anthocyanins from black currants with aqueous ethanol. Journal of Food Scienc. 2003; 68(1):240-248.

21. Prasad KN, Yang B, Yang S, Chen Y, Zhao M, Ashraf M, \& Jiang Y. Identification of phenolic compounds and appraisal of antioxidant and antityrosinase activities from litchi (Litchi sinensis Sonn.) seeds. Food Chemistry. 2009; 116(1):1-7.

22. Luthria DL. Influence of experimental conditions on the extraction of phenolic compounds from parsley (Petroselinum crispum) flakes using a pressurized liquid extractor. Food Chemistry. 2007; 107: $745-752$.

23. Liu XF, Liu L, Wang YG, Leng FF, Wang SW \& Li YC. optimization of total flavonoids extraction from coreopsis tinctoria nutt. by response surface methodology. Kemija $u$ industriji, 2014, 63:391-396.
24. Vijayarathna S, \& Sasidharan S. Cytotoxicity of methanol extracts of Elaeis guineensis on MCF-7 and Vero cell lines. Asian Pacific Journal of Tropical Biomedicine. 2012; 2(10):826-829.

25. Afsharian P, Terelius Y, Hassan Z, Nilsson C, Lundgren S, \& Hassan M. The effect of repeated administration of cyclophosphamide on cytochrome p450 2b in rats. Clinical Cancer Research, 2007; 13(14):4218-4224.

26. Yuan L, Wang J, Wu W, Liu Q, \& Liu X. Effect of isoorientin on intracellular antioxidant defence mechanisms in hepatoma and liver cell lines. Biomedicine \& Pharmacotherapy, 2016; 81:356-362.

27. Gundogdu G, Dodurga Y, Elmas L, Tasci SY, \& Karaoglan ES investigation of the anticancer mechanism of isoorientin isolated from eremurus spectabilis leaves via cell cycle pathways in ht-29 human colorectal adenocarcinoma cells. The Eurasian Journal of Medicine, (2018); 50(3):168-172. 